\title{
Early pancreatic volume reduction on $C T$ predicts relapse in patients with type 1 autoimmune pancreatitis treated with steroids
}

Yoshinori Ohno ${ }^{1}$, Teru Kumagi ${ }^{\text {* }}$, Tomoyuki Yokota ${ }^{2}$, Nobuaki Azemoto ${ }^{3}$, Yoshinori Tanaka ${ }^{4}$, Kazuhiro Tange $^{5}$, Nobu Inada ${ }^{6}$, Hideki Miyata ${ }^{3}$, Yoshiki Imamura', Mitsuhito Koizumi ${ }^{1}$, Taira Kuroda' ${ }^{1}$, Yoichi Hiasa ${ }^{1}$

and on behalf of the EPOCH Study Group

\begin{abstract}
Background: Type 1 autoimmune pancreatitis (AIP) is clinically characterized by a response to steroid therapy. Despite having a favorable prognosis, AIP has a high relapse rate and factors predicting relapse in AIP patients treated with steroids have not yet been established.

Methods: A retrospective chart review was conducted of 32 newly diagnosed type 1 AlP patients who had undergone enhanced computed tomography $(\mathrm{CT})$ pre- and post-steroid therapy.

Results: Ten patients experienced relapse. Pancreatic volume was reduced significantly in all patients (pre-treatment volume, $88.5 \pm 32.9 \mathrm{~cm}^{3}$ vs. post-treatment volume, $45.4 \pm 21.1 \mathrm{~cm}^{3} ; P<0.001$ ), although the pre-treatment pancreatic volume did not differ between the relapse and non-relapse groups $\left(92.6 \pm 10.5 \mathrm{~cm}^{3}\right.$ vs. $\left.86.6 \pm 7.1 \mathrm{~cm}^{3}, P=0.401\right)$. However, the post-treatment pancreatic volume was significantly greater in the relapse group than that in the nonrelapse group $\left(56.9 \pm 6.3 \mathrm{~cm}^{3}\right.$ vs. $\left.40.2 \pm 4.2 \mathrm{~cm}^{3}, P=0.008\right)$. Similarly, the percent reduction in pancreatic volume was significantly smaller in the relapse group than that in the non-relapse group ( $36.6 \pm 4.7 \%$ vs. $52.1 \pm 3.2 \%, P=0.002$ ). Multivariate analysis identified post-treatment pancreatic volume (HR, 1.04, $95 \% \mathrm{Cl}: 1.01-1.08, P=0.010)$ and percent reduction in pancreatic volume $(\mathrm{HR}, 0.87,95 \% \mathrm{Cl}: 0.79-0.94, P<0.001)$ as predictive factors for relapse of type 1 AIP. A post-treatment pancreatic volume of $50 \mathrm{~cm}^{3}<(P=0.009)$ and a percent reduction in the pancreatic volume of $<35 \%$ $(P=0.004)$ had a significantly high relapse rate. These data suggest that early pancreatic volume changes after steroid therapy may be a useful prognostic value, because type 1 AIP patients with a high post-treatment pancreatic volume or low pancreatic volume reduction showed significant relapse.
\end{abstract}

Conclusions: Early pancreatic volume reduction on $C T$ after steroid therapy indicates the therapeutic effects of steroids, and a low decrease in the pancreatic volume may be associated with a limited response that predicts future relapse in patients with type 1 AIP. Reduction of steroids in these cases must be observed carefully with consideration of immunomodulator use.

Keywords: Autoimmune pancreatitis, Relapse factor, Pancreatic volume, Steroid therapy, CT

\footnotetext{
* Correspondence: terukuma@m.ehime-u.ac.jp

${ }^{1}$ Gastroenterology and Metabology, Ehime University Graduate School of

Medicine, Shitsukawa, Toon, Ehime 791-0295, Japan

Full list of author information is available at the end of the article
} 


\section{Background}

Type 1 autoimmune pancreatitis (AIP) is associated with the enlargement of the pancreatic parenchyma, abundant lymphoplasmacytic infiltration and fibrosis, and frequent elevations in the serum immunoglobulin (Ig)-G4 levels. Although the precise pathogenesis of AIP has not yet been determined, AIP is clinically characterized by a response to steroid therapy, and it has a favorable prognosis [1-6]. The remission rate of steroid-treated AIP is $98 \%$, which is significantly higher than $74 \%$ of patients without steroid treatment [7]. However, many patients will experience disease relapse in type 1 AIP, and the relapse rate for this type is $15-64 \%$, according to various studies [7-10]. For most patients in previous reports, relapses occurred after steroid discontinuation [7, 11]. Kamisawa et al. reported that continued maintenance treatment with low-dose prednisolone for 6 months to 3 years is also recommended to prevent relapse in type 1 AIP [7]. Patients who resumed steroid treatment continued to respond favorably with a high remission rate. In addition, some patients with relapse were treated with an immunomodulator $[9,11]$. Although there is general agreement that long-term steroid therapy is the ideal initial treatment for preventing disease relapse, the incidence of steroid-related side effects is a major concern. If predictive factors of relapse or non-relapse in patients with type 1 AIP exist, some patients may not require long-term steroid maintenance therapy, and the incidence of treatment-related side effects may decrease. However, factors that may predict relapse have not yet been established. In this context, the Ehime PancreatoCholangiology (EPOCH) Study Group conducted a retrospective study to identify the predictive factors of relapse in patients with type 1 AIP by focusing on the volume changes in the pancreas.

\section{Methods \\ Patients}

This study included 41 consecutive cases of type 1 AIP according to the clinical diagnostic criteria proposed by the Japan Pancreas Society [12] or the International Consensus of Diagnostic Criteria [13] at six gastroenterology clinics in Ehime (EPOCH Study Group), Japan, from January 2006 to March 2015. Patients who were on steroid therapy before the final diagnosis $(N=2)$, who were not given steroid therapy $(N=3)$, and who did not undergo post-treatment computed tomography (CT) after steroid therapy $(N=4)$ were excluded. Finally, this study included 32 newly diagnosed type 1 AIP patients who underwent enhanced CT pre- and post-treatment.

In 23 patients $(71.9 \%)$, an accompanying pancreatic malignancy was pathologically excluded by an endoscopic ultrasonography-guided fine needle aspiration biopsy $(N=22)$ or by surgical resection $(N=1)$. The median length of follow-up was 36 months (range, 3-107 months). Pre- and post-treatment data collection included demographics (i.e., age and sex), complications (e.g., jaundice and diabetes), markers associated with AIP (i.e., IgG and IgG4), extra-pancreatic lesions detected on $\mathrm{CT}$, and extension of biliary stricture determined by magnetic resonance cholangiopancreatography or endoscopic retrograde cholangiopancreatography (i.e., intrapancreatic, extrapancreatic, and intrahepatic).

\section{CT interval and methods of CT scan measurements}

We measured the volumes of the pancreas as shown on enhanced CT obtained before and within 6 months (median, 1.6 months) after steroid therapy. Early-phase contrast-enhanced CT was used to measure the pancreatic volume, and the slice thickness was as follows: $5 \mathrm{~mm}(N=29), 7 \mathrm{~mm}(N=2)$, and $10 \mathrm{~mm}(N=1)$. The Synapse $^{\oplus}$ Imaging System (Fuji Film) was used to measure the pancreatic volume, which was calculated by summing the manually contoured area of the pancreatic outline of each CT slice. The splenic volume was measured by using the same methods as those for pancreatic volumetry.

\section{Steroid therapy and disease relapse}

The initial daily oral prednisolone dose was determined by body weight $(0.6 \mathrm{mg} / \mathrm{kg}$ per day), and it was $30 \mathrm{mg} /$ day in 27 patients $(84 \%)$. This dosage was administered for about 2 weeks and then was tapered gradually until a daily dose of 5-10 mg was reached, as per each physician's decision. Maintenance steroid therapy was given to all patients, and steroid therapy was discontinued in 4 patients (range, 9-12 months). The median length of steroid therapy was 34 months. The relapsed group was defined as follows: reappearance of the symptoms with reappearance of pancreatic and/or extra-pancreatic abnormalities on imaging studies regardless of the serum IgG or IgG4 levels [7].

\section{Statistical analysis}

The data were analyzed using JMP 9.0 (SAS Institute). Differences and correlations in the pancreatic volume before and after steroid therapy were compared using the Wilcoxon signed-rank test. Receiver operating characteristic (ROC) curves were generated, and the cutoff was determined as the point in the ROC curve that maximized the value of sensitivity plus specificity. Cox proportional hazards regression was used to perform univariate and multivariate analyses of the predictors of disease relapse. Relapse-free survival rates were calculated using the Kaplan-Meier method. P-values <0.05 were considered significant. 


\section{Results}

\section{Clinical profiles}

As shown in Table 1, a total of 32 newly diagnosed type 1 AIP patients were enrolled. Twenty-six patients $(81.3 \%)$ were male, and the median age was 63 years (range, 32-89 years). Patients presented with obstructive jaundice $(N=13)$, abdominal pain or discomfort $(N=$ $13)$, worsening of diabetes $(N=2)$, and abnormal abdominal imaging $(N=4)$. Twenty-three patients $(71.9 \%)$ had diffuse pancreatic swelling and 13 (40.6\%) had jaundice. Patients had the following complications: bile duct stricture $(N=26,81.3 \%)$, all were intrapancreatic but one was intrahepatic; retroperitoneal fibrosis $(N=3,9.4 \%)$; and sialadenitis $(N=2,6.3 \%)$. Twenty patients $(62.5 \%)$ had diabetes: 12 patients preceded the diagnosis of AIP, and 8 patients were diagnosed simultaneously with the diagnosis of AIP. Relapse was observed in 10 patients (31.3\%, relapsed group), with a median duration of 5.0 months (range, 2.1-47.2 months). The reasons for relapse were as follows: symptoms and laboratory data suggestive of bacterial cholangitis with an intrapancreatic bile duct stricture $(N=6)$, acute pancreatitis $(N=3)$, and swelling of the pancreas and the emergence of retroperitoneal fibrosis $(N=1)$ (Table 1$)$. The relapse rate in patients on maintenance therapy was significantly lower than that in those who discontinued maintenance therapy (23\% [7/30 patients] vs. $75 \%$ [3/4 patients]; $P=0.033$ ). Surgeries were performed in 2 patients during the observation period. Pancreatic cancer was suspected in one; however, this was not confirmed, and the other patient had intractable bacterial cholangitis. Finally, all patients survived, except one who died due to a cerebrovascular disease.

Table 1 Clinical findings with type 1 autoimmune pancreatitis

\begin{tabular}{ll}
\hline & Type 1 AIP (N=32) \\
\hline Age (years old) & $63(32-89)$ \\
Imaging of pancreatic parenchyma & $26 / 6$ \\
$\quad$ Diffuse swelling & \\
Elevated serum lgG4 level ( $\geqq 135 \mathrm{mg} / \mathrm{dl})$ & $23(71.9 \%)$ \\
Obstructive Jaundice & $25(78.1 \%)$ \\
Bile duct stricture & $13(40.6 \%)$ \\
$\quad$ Intrapancreatic & \\
$\quad$ Extrapancreatic & $25(78.1 \%)$ \\
$\quad$ Intrahepatic & 0 \\
Retroperitoneal fibrosis & $1(3.1 \%)$ \\
Sialadenitis & $3(9.4 \%)$ \\
Diabetes & $2(6.3 \%)$ \\
Relapse of after steroid therapy & $20(62.5 \%)$ \\
\hline
\end{tabular}

Pancreatic volume change and a comparison of the clinical profiles of the relapse and non-relapse groups after steroid therapy

In all patients, the pancreatic volume on $\mathrm{CT}$ was reduced significantly by steroid therapy (pre-treatment volume, $88.5 \pm 32.9 \mathrm{~cm}^{3}$ vs. post-treatment volume, $45.4 \pm$ $\left.21.1 \mathrm{~cm}^{3} ; P<0.001\right)$, with an average reduction of $47.3 \pm$ $16.5 \%$ (Fig. 1). When the relapse and non-relapse groups were compared, the pancreatic volume did not differ between the two pre-treatment groups $\left(92.6 \pm 10.5 \mathrm{~cm}^{3}\right.$ vs. $\left.86.6 \pm 7.1 \mathrm{~cm}^{3}, P=0.401\right)$. However, the post-treatment pancreatic volume in the relapse group was significantly higher than that in the non-relapse group $\left(56.9 \pm 6.3 \mathrm{~cm}^{3}\right.$ vs. $\left.40.2 \pm 4.2 \mathrm{~cm}^{3} ; P=0.008\right)$. Similarly, the percent reduction in the pancreatic volume was significantly smaller in the relapse group than in the non-relapse group (36.6 \pm $4.7 \%$ vs. $52.1 \pm 3.2 \%, P=0.002$ ). Abdominal CT showed favorable and unfavorable responses to steroid therapy in patients with AIP (Fig. 2). The volume of the spleen on CT was also measured, and it was slightly reduced by steroid therapy (pre-treatment splenic volume, $134.7 \pm$ $58.7 \mathrm{~cm}^{3}$ vs. post-treatment splenic volume, $116.1 \pm$ $\left.51.4 \mathrm{~cm}^{3}, P<0.001\right)$. However, when the relapse and nonrelapse groups were compared, the volume of the spleen did not differ between the two pre-treatment groups. In univariate analysis, variables other than the posttreatment pancreatic volume and percent reduction in the pancreatic volume failed to show an association with relapse (Table 2, Fig. 3). Multivariate analysis used two models and included the post-treatment pancreatic volume (only in Model 1), percent reduction in the pancreatic volume (only in Model 2), diffuse pancreatic swelling, bile duct stricture, and serum IgG4. Finally, the posttreatment pancreatic volume $(\mathrm{HR}=1.04,95 \% \mathrm{CI}$ : $1.01-$ $1.08, P=0.010)$ and percent reduction in the pancreatic volume $(\mathrm{HR}=0.87,95 \% \mathrm{CI}: 0.79-0.94, P<0.001)$ were identified as a predictive factor for relapse in AIP (Table 3). However, diffuse pancreatic swelling, bile duct stricture, and serum IgG4 were not identified as predictive factors.

\section{Predictive factors of relapse}

In the ROC curve analysis, the optimal cut-off value of the post-treatment pancreatic volume and the percent reduction in the pancreatic volume for relapse were determined (Fig. 4, Table 4). A post-treatment pancreatic volume $50 \mathrm{~cm}^{3}<$ (area under the curve [AUC]: 0.72 , sensitivity: $70 \%$, specificity: $81.8 \%, P=0.039$ ) was associated with a significantly high relapse rate in 6 of 10 cases. A percent reduction in the pancreatic volume $<35 \%$ (AUC: 0.77, sensitivity: $60 \%$, specificity: $81.8 \%, P=0.009$ ) was also associated with a significantly high relapse rate in 6 of 9 cases. Furthermore, a post-treatment pancreatic volume $50 \mathrm{~cm}^{3}<$ or a percent reduction in the pancreatic volume $<35 \%$ was associated with a significantly high relapse rate 


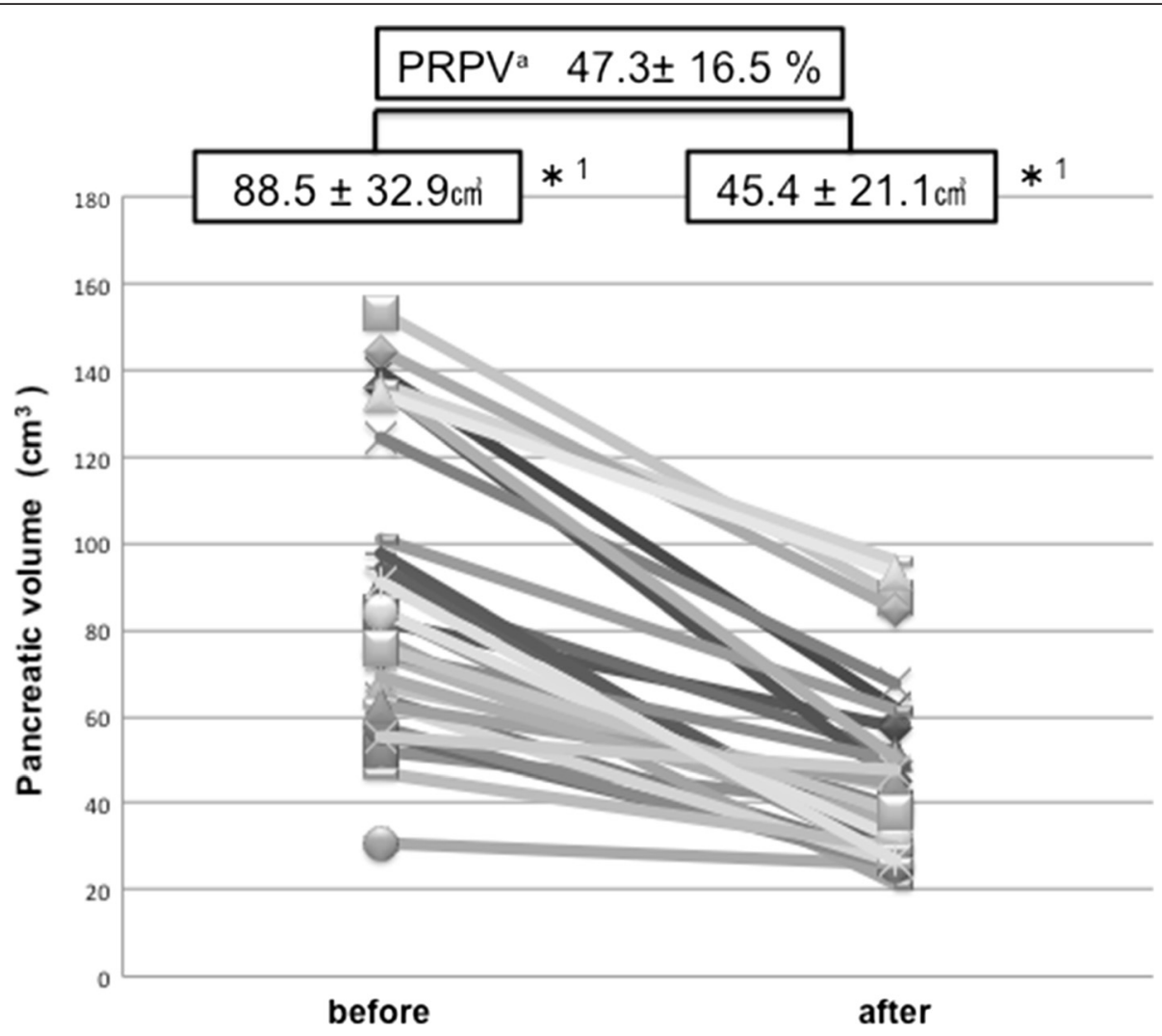

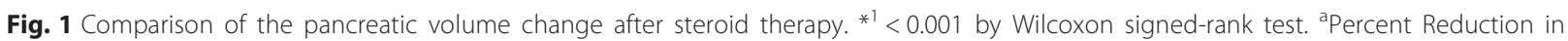
the Pancreatic Volume $=100 \%$ - (pancreatic volume after steroid therapy/pancreatic volume before steroid therapy) $\times 100 \%$
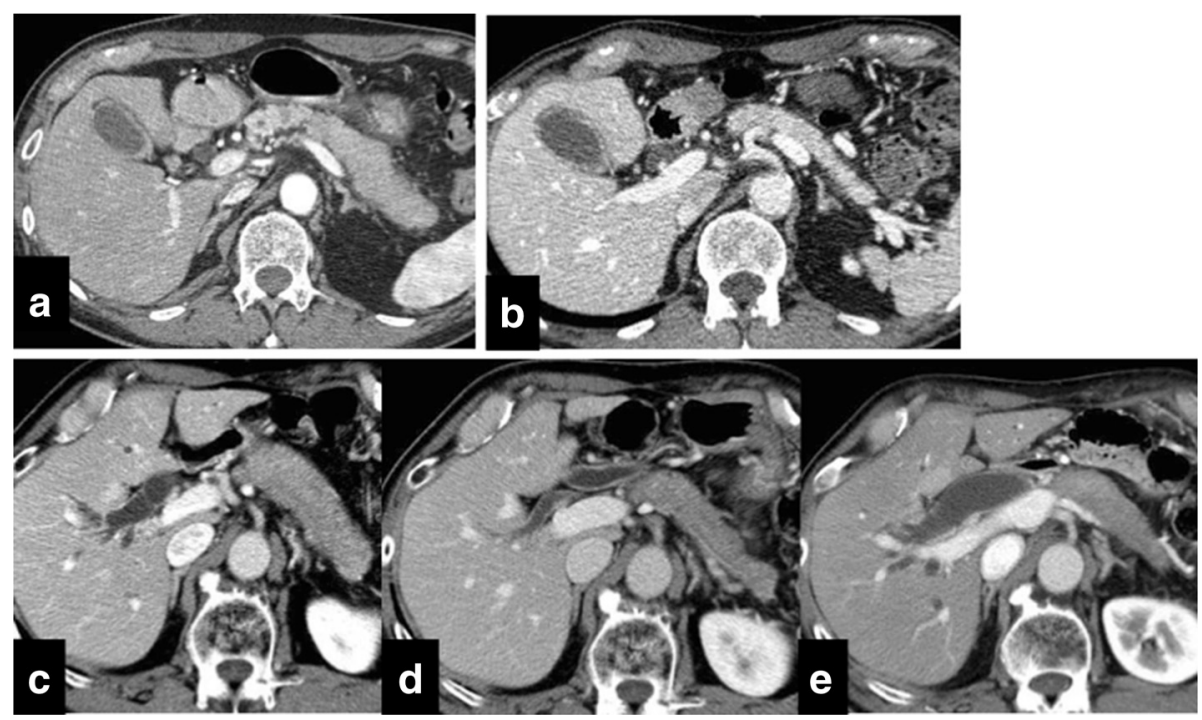

Fig. 2 Abdominal computed tomography showing the pancreas in patients with autoimmune pancreatitis. The post-treatment pancreatic volume was $30.3 \mathrm{~cm}^{3}$, and the percent reduction in the pancreatic volume was $68.2 \%$ in a patient who showed a favorable response without relapse before steroid therapy (a) and 2 weeks after starting steroid therapy (b). The pancreatic volume was not reduced in a patient who showed an unfavorable response with relapse. The post-treatment pancreatic volume was $51.6 \mathrm{~cm}^{3}$, and the percent reduction in the pancreatic volume was $42.3 \%$ before steroid therapy (c) and after 2 months starting steroid therapy (d); at 47 months during relapse, dilatation of the biliary tree (e) was observed 
Table 2 Comparison of the clinicopathologic characteristics in patients

\begin{tabular}{|c|c|c|c|}
\hline \multirow[t]{2}{*}{ Parameter } & \multicolumn{3}{|l|}{ Relapse } \\
\hline & $\begin{array}{l}(+) \\
(N=10)\end{array}$ & $\begin{array}{l}(-) \\
(N=22)\end{array}$ & $P$ value \\
\hline Age (years old) & $61.6 \pm 3.6$ & $60.5 \pm 2.4$ & 0.799 \\
\hline Gender (male) & 8 & 18 & 0.732 \\
\hline $\begin{array}{l}\text { Imaging of pancreatic } \\
\text { parenchyma (Diffuse) }\end{array}$ & 8 & 15 & 0.897 \\
\hline $\operatorname{lgG}(\mathrm{mg} / \mathrm{dl})$ & $2020 \pm 298$ & $1877 \pm 205$ & 0.398 \\
\hline $\operatorname{lgG} 4(\mathrm{mg} / \mathrm{dl})$ & $525 \pm 124$ & $368 \pm 84$ & 0.483 \\
\hline Obstructive jaundice & 4 & 9 & 0.560 \\
\hline Bile duct stricture ${ }^{a}$ & 8 & 17 & 0.795 \\
\hline Extra-pancreatic lesions ${ }^{b}$ & 2 & 4 & 0.988 \\
\hline Diabetes & 5 & 15 & 0.268 \\
\hline $\begin{array}{l}\text { Pre-treatment pancreatic } \\
\text { volume }\left(\mathrm{cm}^{3}\right)\end{array}$ & $92.6 \pm 10.5$ & $86.6 \pm 7.1$ & 0.401 \\
\hline $\begin{array}{l}\text { Post-treatment pancreatic } \\
\text { volume }\left(\mathrm{cm}^{3}\right)\end{array}$ & $56.9 \pm 6.3$ & $40.2 \pm 4.2$ & $0.008^{*}$ \\
\hline $\begin{array}{l}\text { Percent reduction of pancreatic } \\
\text { volume (\%) }\end{array}$ & $36.6 \pm 4.7$ & $52.1 \pm 3.2$ & $0.002^{*}$ \\
\hline $\begin{array}{l}\text { Pre-treatment splenic } \\
\text { volume }\left(\mathrm{cm}^{3}\right)\end{array}$ & $133.9 \pm 18.9$ & $135.0 \pm 12.7$ & 0.959 \\
\hline $\begin{array}{l}\text { Post-treatment splenic } \\
\text { volume }\left(\mathrm{cm}^{3}\right)\end{array}$ & $116.5 \pm 16.5$ & $116.0 \pm 11.1$ & 0.836 \\
\hline $\begin{array}{l}\text { Percent reduction of splenic } \\
\text { volume (\%) }\end{array}$ & $13.5 \pm 6.3$ & $12.3 \pm 4.2$ & 0.616 \\
\hline
\end{tabular}

${ }^{a}$ Intrapancreatic bile duct stricture, except extrapancreatic and intrahepatic bile duct stricture

${ }^{\mathrm{b}}$ Intrahepatic bile duct stricture, retroperitoneal fibrosis, and sialadenitis

* $<0.05$ by Cox proportional hazards regression analysis
$(P=0.002)$ in 9 of 16 cases. On the other hand, a posttreatment pancreatic volume $\leq 50 \mathrm{~cm}^{3}$ and a percent reduction in the pancreatic volume $35 \% \leq$ had significantly lower relapse rate, with a relapse in only $1 / 16$ case.

\section{Discussion}

The histologic pattern of type 1 AIP is called lymphoplasmacytic sclerosing pancreatitis, which is characterized by a periductal lymphoplasmacytic infiltrate, storiform fibrosis, and obliterative venulitis [3, 4]. In our study, the pancreatic volume on CT significantly reduced by steroid therapy in all patients. However, when the relapse and non-relapse groups were compared, the change in pancreatic volume after steroid therapy was significantly different. These findings may suggest that the pancreatic volume change after steroid therapy reflects the histological findings in the pancreas. According to the histological findings previously reported, the pancreatic parenchyma was replaced by massive or extensive interlobular fibrosis with lymphoplasmacytic infiltrates to varying degrees in advanced stages of type 1 AIP [14]. However, the pancreatic volumetric blood flow of perfusion CT was attenuated in AIP, which improved after steroid treatment [15]. The pancreatic volumetric blood flow after steroid treatment may reflect the histological disease stage of type 1 AIP. Ko et al. reported that the number of IgG4-positive plasma cells in pancreatic tissue was decreased by steroid treatment, indicating a reduction in inflammation [16]. Nevertheless, changes in the histopathology after steroid treatment for AIP are still unclear. Matsubayashi et al. reported a reduction in the splenic volume by steroid therapy in cases with AIP [17]. In our study, although the volume of the spleen

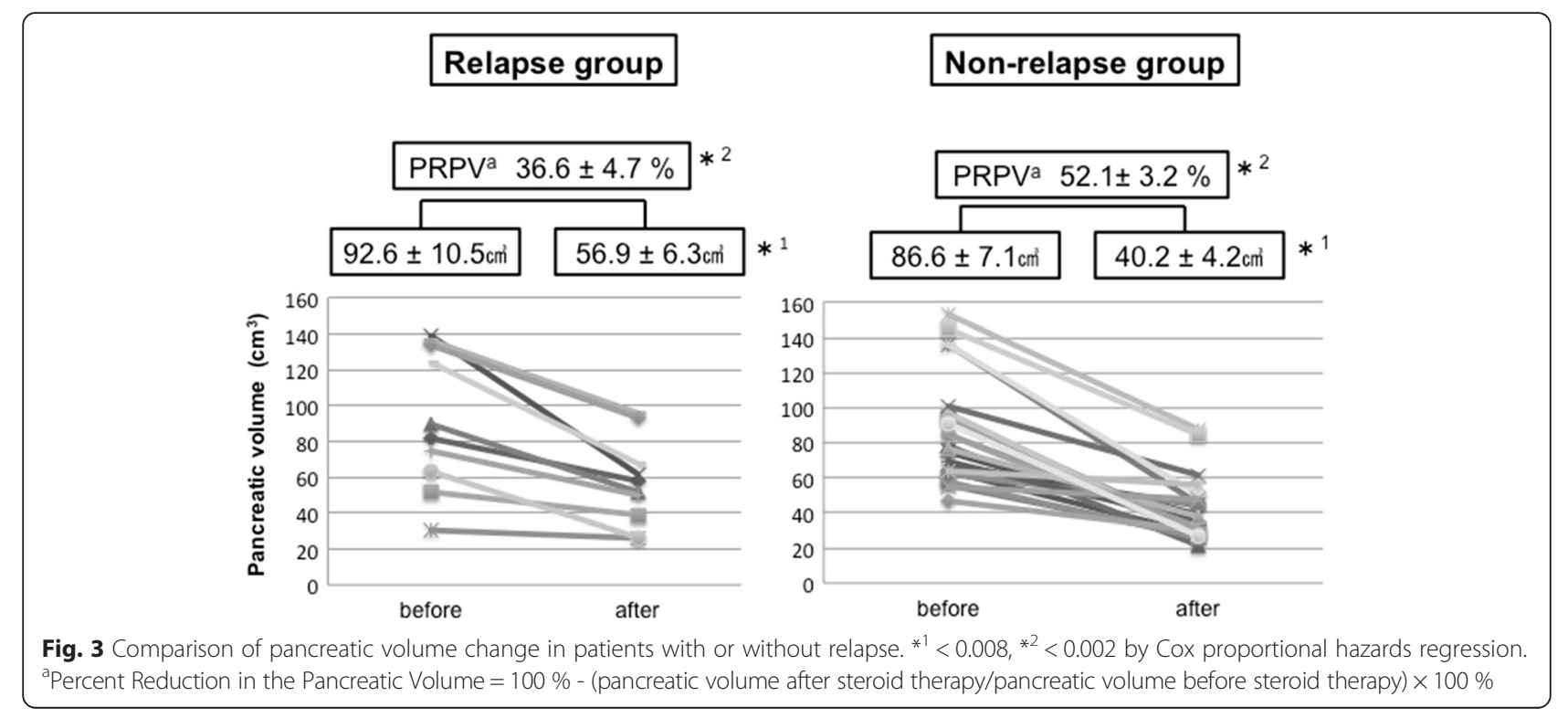


Table 3 Results of multivariate analysis for disease relapse in patients with AIP

\begin{tabular}{llll}
\hline & HR & $95 \% \mathrm{Cl}$ & $P$ value \\
\hline Model 1 & & & \\
Post-treatment pancreatic volume & 1.04 & $1.01-1.08$ & 0.010 \\
Model 2 & & & \\
Percent reduction in the pancreatic volume & 0.87 & $0.79-0.94$ & $<0.001$ \\
\hline
\end{tabular}

Data are based on Cox proportional hazards regression

Model 1: post-treatment pancreatic volume, diffuse pancreatic swelling, bile duct stricture (intrapancreatic bile duct stricture, except extrapancreatic and intrahepatic bile duct stricture), and serum $\lg G 4$

Model 2: percent reduction in the pancreatic volume, diffuse pancreatic swelling, bile duct stricture (intrapancreatic bile duct stricture, except extrapancreatic and intrahepatic bile duct stricture), and serum lgG4

was reduced by steroid therapy, it did not differ between the relapse and non-relapse groups.

In an analysis of 463 patients with AIP among 15 institutes in eight countries, Kamisawa et al. reported that the relapse rate in patients treated with steroid ranged 15$64 \%$ [10]. The relapse rates in Western countries were higher than those in Asian countries (United States, $64 \%$ vs. Japan, $15 \%$ ). The difference in the relapse rate was presumably due to the period from administration to cessation of steroid therapy (United States, 3 months vs. Japan, 1-2 years). Indeed, the majority of relapse episodes occurred in steroid-treated subjects following steroid discontinuation compared to those in whom the steroid dose was being tapered or were on steroid maintenance therapy $[7,11]$. Continued maintenance treatment with low-dose prednisolone for 6 months to 3 years is also recommended to prevent relapse [7]. Although there is general agreement that long-term steroid therapy is the ideal initial treatment for preventing disease relapse, the incidence of steroid-related side effects is a major concern. Shimizu et al. reported that the cumulative dose of corticosteroids was significantly higher in patients with serious side effects than in those without [18]. In our cases, maintenance steroid therapy was given to all patients, and steroid therapy was discontinued in only 4 patients. Some relapsed patients are treated with an immunomodulator such as azathioprine $[9,11]$, and these steroid-sparing approaches

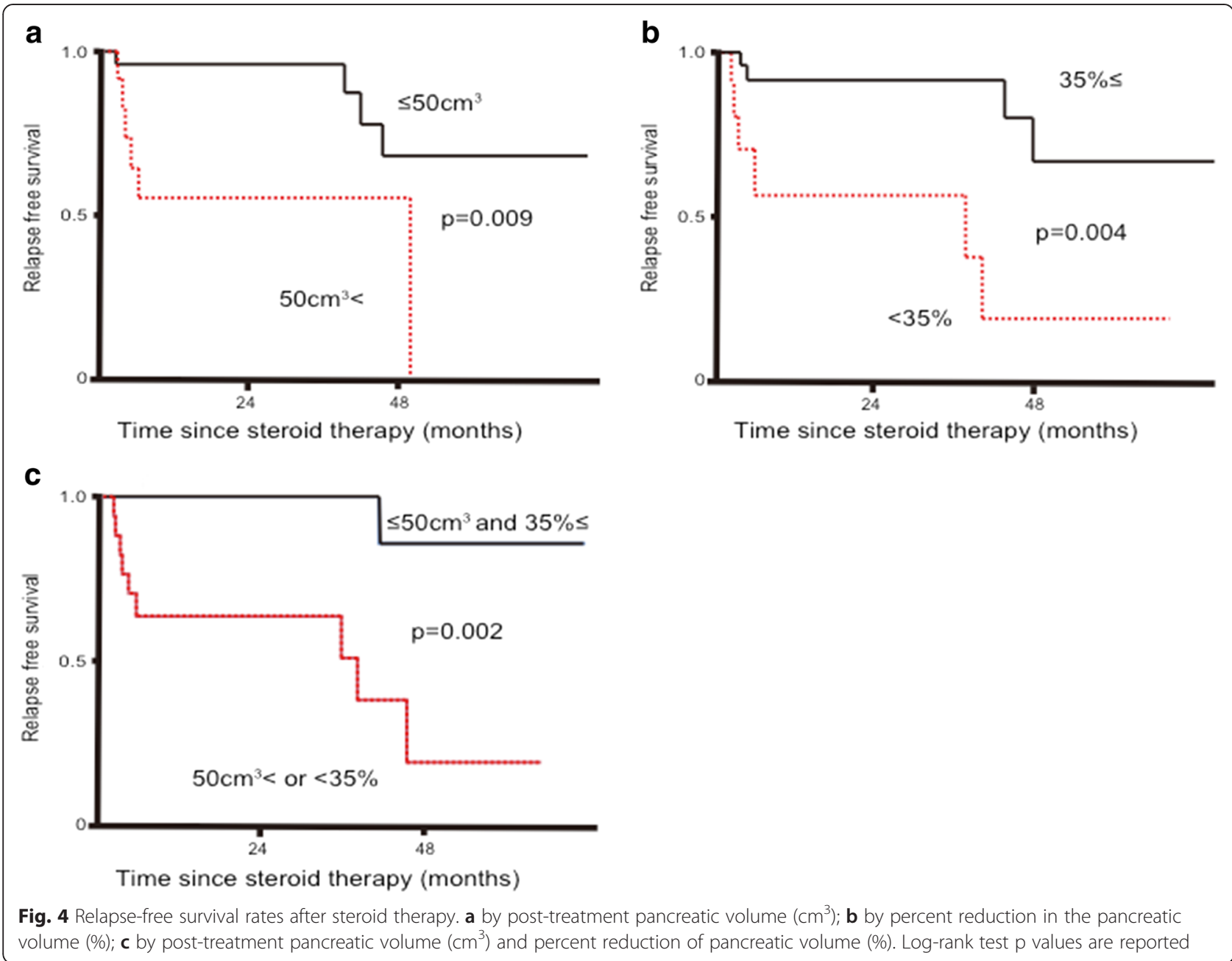


Table 4 Relationship between post-treatment pancreatic volume and percent reduction in the pancreatic volume in relapse cases

\begin{tabular}{llll}
\hline & & \multicolumn{2}{l}{$\begin{array}{l}\text { Post-treatment pancreatic } \\
\text { volume }\left(\mathrm{cm}^{3}\right)\end{array}$} \\
\cline { 2 - 4 } & & $\leq 50$ & $50<$ \\
\hline Percent reduction in the pancreatic & $<35$ & $3 / 6$ & $3 / 3$ \\
volume (\%) & $35 \leq$ & $1 / 16$ & $3 / 7$ \\
\hline
\end{tabular}

are attractive for preventing complications from longterm steroid exposure [19-22].

There are some reports regarding the relapse factors in AIP. Diffuse pancreatic swelling was a predictive factor of relapse [11]. The relapse rate of AIP was higher in patients with IgG4-related sclerosing cholangitis (SC) than in those without IgG4-related SC (56.1 \% vs. $25.7 \%$, respectively) [11]. IgG4 seropositivity and jaundice are at a higher risk of relapse, and IgG4 seronegativity have a high likelihood of spontaneous remission [23]. Diffuse pancreatic swelling and proximal biliary involvement are predictive of relapse in type 1 AIP [8], whereas distal biliary involvement was not predictive in cases of type 1 AIP [11]. Additionally, positive staining of the duodenal papilla for IgG4 and a swollen duodenal papilla had a favorable response to steroid therapy [24]. However, factors that may predict relapse have not been well defined, and some are still controversial. Indeed, our study failed to show that the diffuse type IgG4 seropositivity and jaundice were predictive factors of relapse. Moreover, these factors are examined at the time of diagnosis, and they are not intended to reflect the course of treatment.

Over the course of treatment, our findings suggest that early pancreatic volume changes after steroid therapy may be a useful prognostic value, because patients with AIP with a high post-treatment pancreatic volume $\left(50 \mathrm{~cm}^{3}<\right)$ or low pancreatic volume reduction $(<35 \%)$ showed a significant relapse. Reduction of steroids in these cases must be observed carefully with consideration of immunomodulator use, such as azathioprine.

On the other hand, patients who had a post-treatment pancreatic volume $\leq 50 \mathrm{~cm}^{3}$ and a percent reduction in the pancreatic volume $35 \% \leq$ had a significantly lower relapse rate. In other words, a low post-treatment pancreatic volume and a high pancreatic volume reduction may predict non-relapse in patients with AIP. Therefore, these measures may be useful for selecting suitable candidates for steroid discontinuation to prevent treatmentrelated side effects. However, Masuda et al. reported that AIP patients with pancreatic atrophy after steroid therapy have a high incidence of diabetes mellitus [25]. Although our cases did not fit into the definition of pancreatic atrophy proposed by Hirano et al. [26] at the time of CT measurement after steroid therapy, some cases might further reduce their pancreatic volume with a longer period of steroid therapy and develop diabetes. These reports also support the abovementioned idea to discontinue steroid in selected patients.

As is common for studies with retrospective designs, our study has the following limitations: small sample size; not all patients underwent a histological examination; and the steroid treatment regimen, period of steroid therapy, and timing of CT were not uniform. To overcome these limitations, further long-term prospective studies in a larger cohort are needed to examine the relationship between the pancreas volume reduction and relapse in AIP treated with steroids. Nevertheless, we believe that our findings currently present one of the best factors for predicting relapse in patients with AIP.

\section{Conclusions}

Early pancreatic volume reduction on CT after steroid therapy reflects therapeutic effects of steroid and predicts future relapse in patients with type 1 AIP. Reduction of steroids in these cases must be observed carefully with consideration of immunomodulator use.

\section{Abbreviations \\ AIP, autoimmune pancreatitis; $C T$, computed tomography}

\section{Acknowledgement}

Not applicable.

\section{Funding}

This work was supported in part by a Grant-in-Aid for Scientific Research (Japan Society for the Promotion of Science, KAKENHI 26461034) provided to T. Kumagi.

\section{Availability of data and materials}

The authors confirm that all data underlying the findings are fully available without restriction. All subjects were assigned a numerical code that was used throughout the study, and all data were stored in a secure database to maintain anonymity.

\section{Authors' contributions}

Study concept and design (YO, TKum); acquisition of data (YO, TY, NA, YT, KT, $\mathrm{NI}, \mathrm{HM}, \mathrm{YI})$; analysis and interpretation of data (YO, TKum); drafting of the manuscript (YO, TKum, MK, TKur, YH); critical revision of the manuscript for important intellectual content (YO, TKum, TY, NA, YT, KT, NI, HM, YI, MK, TKur, $\mathrm{YH})$; statistical analysis (YO, TKum); study supervision (TKum, YH). All authors read and approved the final manuscript.

\section{Competing interests \\ The authors declare that they have no competing interests.}

\section{Consent for publication}

Not applicable.

\section{Ethics approval and consent to participate}

The study protocol conformed to the ethical guidelines of the 1975 Declaration of Helsinki and was approved by the local ethics committee at the Ehime University Graduate School of Medicine (Approval No. 1505010). Written consent form was waived due to the retrospective manner.

\section{Author details}

'Gastroenterology and Metabology, Ehime University Graduate School of Medicine, Shitsukawa, Toon, Ehime 791-0295, Japan. ${ }^{2}$ Center for Liver-Biliary-Pancreatic Diseases, Matsuyama Red Cross Hospital, Matsuyama 
790-8524, Ehime, Japan. ${ }^{3}$ Gastroenterology, Ehime Prefectural Central Hospital, Matsuyama 790-0024, Ehime, Japan. ${ }^{4}$ Gastroenterology, Matsuyama Municipal Hospital, Matsuyama 790-0067, Ehime, Japan. ${ }^{5}$ Internal Medicine, Saiseikai Imabari Hospital, Imabari 799-1502, Ehime, Japan. ${ }^{6}$ Internal Medicine, Saiseikai Matsuyama Hospital, Matsuyama 791-8026, Ehime, Japan.

Received: 3 April 2016 Accepted: 19 July 2016

Published online: 28 July 2016

\section{References}

1. Hamano H, Kawa S, Horiuchi A, Unno H, Furuya N, Akamatsu T, et al. High serum lgG4 concentrations in patients with sclerosing pancreatitis. N Engl J Med. 2001;344:732-8.

2. Yoshida K, Toki F, Takeuchi, Watanabe S, Shiratori K, Hayashi N. Chronic pancreatitis caused by an autoimmune abnormality. Proposal of the concept of autoimmune pancreatitis. Dig Dis Sci. 1995;40:1561-8.

3. Park DH, Kim MH, Chari ST. Recent advances in autoimmune pancreatitis. Gut. 2009:58:1680-9.

4. Zhang L, Notohara K, Levy MJ, Chari ST, Smyrk TC. IgG4-positive plasma cell infiltration in the diagnosis of autoimmune pancreatitis. Mod Pathol. 2007;20:23-8.

5. Yamanishi H, Kumagi T, Yokota T, Azemoto N, Koizumi M, Kobayashi Y, et al. Clinical significance of $B$ cell-activating factor in autoimmune pancreatitis. Pancreas. 2011:40:840-5.

6. Seleznik GM, Reding T, Romrig F, Saito Y, Mildner A, Segerer S, et al. Lymphotoxin $\beta$ receptor signaling promotes development of autoimmune pancreatitis. Gastroenterology. 2012;143:1361-74.

7. Kamisawa T, Shimosegawa T, Okazaki K, Nishino T, Watanabe H, Kanno A, et al. Standard steroid treatment for autoimmune pancreatitis. Gut. 2009;58:1504-7.

8. Sah RP, Chari ST, Pannala R, Sugumar A, Clain JE, Levy MJ, et al. Differences in clinical profile and relapse rate of type 1 versus type 2 autoimmune pancreatitis. Gastroenterology. 2010;139:140-8.

9. Sandanayake NS, Church NI, Chapman MH, Johnson GJ, Dhar DK, Amin Z, et al. Presentation and management of post-treatment relapse in autoimmune pancreatitis/immunoglobulin G4-associated cholangitis. Clin Gastroenterol Hepatol. 2009;7:1089-96.

10. Kamisawa T, Chari ST, Giday SA, Kim MH, Chung JB, Lee KT, et al. Clinical profile of autoimmune pancreatitis and its histological subtypes: an international multicenter survey. Pancreas. 2011;40:809-14.

11. Hart PA, Kamisawa T, Brugge WR, Chung JB, Culver EL, Czakó L, et al. Longterm outcomes of autoimmune pancreatitis: a multicentre, international analysis. Gut. 2013;62:1771-6.

12. The Japan Pancreas Society, the Ministry of Health and Welfare Investigation Research Team for Intractable Pancreatic Disease. Clinical diagnostic criteria for autoimmune pancreatitis 2011 (in Japanese with English Abstract). J Jpn Pancreas (Suizou). 2012;27:17-25.

13. Shimosegawa T, Chari ST, Frulloni L, Kamisawa T, Kawa S, Mino-Kenudson M, et al. International consensus diagnostic criteria for autoimmune pancreatitis: guidelines of the International Association of Pancreatology. Pancreas. 2011;40:352-8.

14. Suda K, Nishimori I, Takase M, Oi I, Ogawa M. Autoimmune pancreatitis can be classified into early and advanced stages. Pancreas. 2006:33:345-50.

15. Hirota M, Tsuda M, Tsuji Y, Kanno A, Kikuta K, Kume K, et al. Perfusion computed tomography findings of autoimmune pancreatitis. Pancreas. 2011:40:1295-301.

16. Ko SB, Mizuno N, Yatabe $Y$, Yoshikawa T, Ishiguro H, Yamamoto A, et al. Corticosteroids correct aberrant CFTR localization in the duct and regenerate acinar cells in autoimmune pancreatitis. Gastroenterology. 2010;138:1988-96.

17. Matsubayashi H, Uesaka K, Kanemoto H, Aramaki T, Nakaya Y, Kakushima N, et al. Reduction of splenic volume by steroid therapy in cases with autoimmune pancreatitis. J Gastroenterol. 2013;48:942-50.

18. Shimizu S, Naitoh I, Nakazawa T, Hayashi K, Miyabe K, Kondo H, et al. Correlation between long-term outcome and steroid therapy in type 1 autoimmune pancreatitis: relapse, malignancy and side effect of steroid. Scand J Gastroenterol. 2015;50:1411-8.

19. Kamisawa T, Okazaki K, Kawa S, Shimosegawa T, Tanaka M, Research Committee for Intractable Pancreatic Disease and Japan Pancreas Society. Japanese consensus guidelines for management of autoimmune pancreatitis: III. Treatment and prognosis of AIP. J Gastroenterol. 2010:45:471-7.

20. Raina A, Yadav D, Krasinskas AM, McGrath KM, Khalid A, Sanders M, et al. Evaluation and management of autoimmune pancreatitis: experience at a large US center. Am J Gastroenterol. 2009;104:2295-306.

21. Ghazale A, Chari ST, Zhang L, Smyrk TC, Takahashi N, Levy MJ, et al. Immunoglobulin G4-associated cholangitis: clinical profile and response to therapy. Gastroenterology. 2008:134:706-15.

22. Zen Y, Bogdanos DP, Kawa S. Type 1 autoimmune pancreatitis. Orphanet Rare Dis. 2011;6:82.

23. Kubota K, Watanabe S, Uchiyama T, Kato S, Sekino Y, Suzuki K, et al. Factors predictive of relapse and spontaneous remission of autoimmune pancreatitis patients treated/not treated with corticosteroids. J Gastroenterology. 2011:46:834-42.

24. Kubota $K$, lida H, Fujisawa T, Yoneda M, Inamori M, Abe $Y$, et al. Clinical factors predictive of spontaneous remission or relapse in cases of autoimmune pancreatitis. Gastrointest Endosc. 2007;66:1142-51.

25. Masuda A, Shiomi H, Matsuda T, Takenaka M, Arisaka Y, Azuma T, et al. The relationship between pancreatic atrophy after steroid therapy and diabetes mellitus in patients with autoimmune pancreatitis. Pancreatology. 2014;14:361-5.

26. Hirano K, Tada M, Isayama H, Watanabe T, Saito T, Uchino R, et al. High alcohol consumption increases the risk of pancreatic stone formation and pancreatic atrophy in autoimmune pancreatitis. Pancreas. 2013;42:502-5.

\section{Submit your next manuscript to BioMed Central and we will help you at every step:}

- We accept pre-submission inquiries

- Our selector tool helps you to find the most relevant journal

- We provide round the clock customer support

- Convenient online submission

- Thorough peer review

- Inclusion in PubMed and all major indexing services

- Maximum visibility for your research

Submit your manuscript at www.biomedcentral.com/submit

) Biomed Central 